\title{
Cytoreductive surgery in combination with hyperthermic intraperitoneal chemotherapy improves survival in patients with colorectal peritoneal metastases compared with systemic chemotherapy alone
}

R Mirnezami ${ }^{1}$, A M Mehta ${ }^{2}, \mathrm{~K}$ Chandrakumaran $^{3}, \mathrm{~T} \mathrm{Cecil}^{3}, \mathrm{~B} \mathrm{~J} \mathrm{Moran}^{3}$, N Carr ${ }^{3}$, V J Verwaal ${ }^{2,5}, \mathrm{~F} \mathrm{Mohamed}^{3,5}$ and $\mathrm{A} \mathrm{H}$ Mirnezami ${ }^{\star, 4,5}$

${ }^{1}$ Section of Biosurgery and Surgical Technology, Department of Surgery and Cancer, Imperial College London, St Mary's Hospital, 10th Floor QEQM Building, London W2 1NY, UK; ${ }^{2}$ Peritoneal Surface Malignancy Unit, Department of Surgical Oncology, The Netherlands Cancer Institute - Antoni van Leeuwenhoek Hospital, Plesmanlaan 121, Amsterdam 1066 CX, The Netherlands; ${ }^{3}$ Peritoneal Malignancy Institute, Basingstoke and North Hampshire Hospital, Aldermaston Road, Basingstoke, Hampshire RG24 9NA, UK and ${ }^{4}$ University of Southampton Cancer Sciences Division, Southampton University Hospital NHS Trust, Somers Cancer Research Building, Tremona road, Southampton SO166YD, UK

Background: Colorectal cancer peritoneal metastasis (CPM) confers an exceptionally poor prognosis, and traditional treatment involving systemic chemotherapy (SC) is largely ineffective. Cytoreductive surgery (CRS) combined with hyperthermic intraperitoneal chemotherapy (HIPEC) is increasingly advocated for selected patients with CPM; however, opinions are divided because of the perceived lack of evidence, high morbidity, mortality, and associated costs for this approach. As there is no clear consensus, the aim of this study was to compare outcomes following CRS + HIPEC vs SC alone for CPM using meta-analytical methodology, focusing on survival outcomes. Secondary outcomes assessed included morbidity, mortality, quality of life (QOL), and health economics (HE).

Methods: An electronic literature search was conducted to identify studies comparing survival following CRS + HIPEC vs SC for CPM. The odds ratio (OR) was calculated using the Mantel-Haenszel method with corresponding $95 \%$ confidence intervals (Cl) and $P$-values. Heterogeneity was examined using the $Q$-statistic and quantified with $P^{2}$. The fixed-effect model (FEM) was used in the absence of significant heterogeneity. For included studies, 2- and 5-year survival was compared for CRS + HIPEC vs SC alone.

Results: Four studies (three case-control, one RCT) provided comparative survival data for patients undergoing CRS + HIPEC $(n=187)$ vs SC $(n=155)$ for CPM. Pooled analysis demonstrated superior 2-year (OR 2.78; 95\% Cl 1.72-4.51; $P=0.001)$ and 5 -year (OR 4.07; 95\% $\mathrm{Cl} 2.17-7.64 ; P=0.001)$ survival with CRS + HIPEC compared with $\mathrm{SC}$. Mortality ranged from 0 to $8 \%$. No data were available for the assessment of $\mathrm{QOL}$ or $\mathrm{HE}$.

Conclusions: Although limited by between-study heterogeneity, the data support the assertion that in carefully selected patients, multimodal treatment of CPM with CRS + HIPEC has a highly positive prognostic impact on medium- and long-term survival compared with SC alone. There is a paucity of comparative data available on morbidity, $\mathrm{QOL}$, and $\mathrm{HE}$.

*Correspondence: Associate Professor AH Mirnezami; E-mail: ahm@soton.ac.uk

${ }^{5}$ These authors contributed equally to this work.

Received 18 April 2014; accepted 30 June 2014; published online 16 September 2014

(c) 2014 Cancer Research UK. All rights reserved 0007-0920/14 
Colorectal carcinoma (CRC) is a key public health issue and accounts for the second highest cause of cancer-related death in Europe (Ferlay et al, 2013). Metastases are the principal causes of death and occur in $30 \%$ of patients at presentation (Cunningham et al, 2010) and subsequently in over $50 \%$ following surgery with curative intent (Cunningham et al, 2010). Although historically the presence of metastases has been regarded with pessimism and as a symbol of incurability, the last three decades have seen remarkable advances in the multimodality management of metastatic CRC, with combinations of neoadjuvant and adjuvant chemotherapy regimens (Cunningham et al, 2004), radiotherapy (Lee et al, 2013), and radical surgery (van Dijk et al, 2013; Yi et al, 2013) increasingly deployed to combat metastases. These approaches have led to improved oncological outcomes in selected patients, and even long-term survivorship notwithstanding distant spread. Despite a paucity of high-quality randomised studies to direct this shift, the dramatic results seen with these pragmatic approaches have been persuasive, and multimodality treatment of liver and lung metastases is now the standard of care in many institutions (Tampellini et al, 2012; Nordlinger et al, 2013).

One area of contention in the management of metastases from CRC has been the treatment of peritoneal metastases. Approximately $5-10 \%$ of patients undergoing CRC resection are found to have synchronous peritoneal metastases (Chu et al, 1989; Sadeghi et al, 2000; Jayne et al, 2002), whereas a further $20-50 \%$ go on to experience metachronous intraperitoneal recurrence (Sadeghi et al, 2000). Conventional treatment of colorectal cancer peritoneal metastasis (CPM) involving systemic chemotherapy (SC), with or without palliative surgery, has a poor outlook with a median survival of 5-7 months (Chu et al, 1989; Sadeghi et al, 2000; Jayne et al, 2002). In more recent times, however, a radical multimodality locoregional approach combining cytoreductive surgery (CRS) and hyperthermic intraperitoneal chemotherapy (HIPEC) has been advocated as a treatment option and is offered in a growing number of specialist units (Glehen et al, 2010; Kuijpers et al, 2013; Riss et al, 2013). The aim of this approach is to remove all macroscopic disease through peritoneal stripping and multivisceral resections where required, followed by administering hyperthermic chemotherapy intraoperatively into the abdomen to treat residual microscopic disease. This method achieves high intraperitoneal concentrations of cytotoxic drugs, avoids significant systemic absorption, and additionally offers a synergistic cytotoxic effect from the combination of hyperthermia and chemotherapy (Brucher et al, 2012).

Support for this approach has been largely based on a small number of studies showing improved survival outcomes with CRS and HIPEC compared with SC alone (Verwaal et al, 2008; Elias et al, 2009). Despite these encouraging reports, the relative lack of level-1 evidence and concerns with respect to peri-operative morbidity, mortality, and health-care costs has divided opinion regarding these aggressive multimodality approaches, and the optimal management of CPM, therefore, remains controversial (Khatri, 2010).

The present study provides a meta-analytical evaluation of survival outcomes with CRS combined with HIPEC (CRS + HIPEC) compared with SC alone. To our knowledge, this is the first pooled analysis to have synthesised data from multiple studies assessing the role of CRS and HIPEC, specifically in the context of CPM.

\section{MATERIALS AND METHODS}

Identification of studies. An electronic literature search was carried out using MEDLINE (1965-September 2013), EMBASE (1980-September 2013), CINAHL (1982-September 2013), and the Cochrane Library databases. The following medical subject heading terms and key words were used: 'colorectal cancer'; 'peritoneal'; 'carcinomatosis'; 'cytoreductive surgery'; 'chemotherapy'; 'intraoperative'; and 'intraperitoneal'. The 'related articles' function was used to broaden the search and all abstracts, studies and citations retrieved were scanned for subject relevance. The latest date of this search was January 2014. All potentially relevant publications were retrieved in full text and formally evaluated for study inclusion. Reference lists of all relevant publications were hand-searched for additional studies missed by the search strategy, and this method of cross-referencing was continued until no further relevant publications were identified.

Study inclusion criteria and data extraction. Study methodology was carried out in accordance with the 'Preferred Reporting Items for Systematic Reviews and Meta-Analyses' (PRISMA) recommendations for improving the standard of systematic reviews (Moher et al, 2009). Included studies had to provide comparative survival outcome data in $\geqslant 15$ male/female adult patients ( $\geqslant 18$ years) with a histologically confirmed diagnosis of primary or recurrent CPM undergoing treatment with either CRS + HIPEC or SC alone. Studies reporting comparative outcomes for cancer subtypes other than colorectal were only included if survival outcome data were reported independently for CPM cases. Only English language publications were included. Two reviewers (RM and AHM) independently extracted the following data from all eligible studies according to a predetermined protocol: First author, year of publication, study location, study type, study time frame, population characteristics, number of subjects, primary or recurrent disease, stage of CPM (peritoneal cancer index (PCI; Jacquet and Sugarbaker, 1996) or alternative scoring method for disease extent), chemotherapeutic regimen, details of previous treatment (chemotherapy/radiotherapy), follow-up duration, incidence of morbidity and mortality, completeness of cytoreduction (CCR, CCR score (Sugarbaker, 1999) and/or R-classification where reported), and 2- and 5-year survival (overall and/or disease-free). In cases of doubt, authors were contacted for further information to ensure accuracy. Where actuarial survival outcomes were not reported for 2 and 5 years specifically, and authors could not be contacted, data were digitally extracted from Kaplan-Meier survival plots using graphic digitisation software (DigitizeIt, Braunschweig, Germany) according to previously published methodology (Guyot et al, 2012). Data from studies including mucinous appendiceal tumours were excluded, unless the data were separately evaluable. Extracted data were entered into a computerised database and cross-checked to reach consensus. Included studies were subjected to an assessment of methodological quality and validity and graded on strength of evidence using the revised grading system of the Scottish Intercollegiate Guidelines Network (Harbour and Miller, 2001).

Statistical analysis. Statistical analysis was performed using Comprehensive Meta-analysis Version 2, Biostat (Englewood, NJ, USA) to derive odds ratios (ORs) with corresponding 95\% confidence intervals (CIs) for 2- and 5-year survival with CRS + HIPEC vs SC alone. Between-study heterogeneity was assessed using Cochran's $Q$-test and further quantified using the $I^{2}$ statistic. The Q-statistic is underpowered and therefore homogeneity of studies was assumed at a $P$-value greater than 0.1 (Song et al, 2001). The $I^{2}$ statistic is derived independently of the number of studies and indicates low heterogeneity at or below 25\% (Higgins and Thompson, 2002; Higgins et al, 2003). Overall pooled OR for 2- and 5-year survival with 95\% CI was calculated using the fixedeffect model (FEM), in the absence of significant study heterogeneity. The relative weight conferred to each study is inversely proportional to the variance associated with the OR and is represented by squares in the forest plots. The pooled estimate is represented by a diamond in the forest plots, the width of which corresponds to the $95 \%$ CI. Publication bias was assessed visually with funnel plots and Egger's regression test (Egger et al, 1997; 
Sutton et al, 2000). No significant publication bias was assumed if the $95 \%$ CI included 0.

\section{RESULTS}

Literature search and description of studies. Our predefined search strategy identified a total of 265 potentially relevant publications. Following screening of titles and abstracts, 175 articles were excluded, leaving 90 publications that were retrieved in full text. A bibliographic search from these articles identified three additional studies providing a total of 93 articles for detailed evaluation. Of these, 89 were subsequently withdrawn leaving a total of four studies published between 2004 and 2010 that were entered into the review process. Figure 1 provides a summary of the outlined search strategy.

Three case-control studies (Mahteme et al, 2004; Elias et al, 2009; Franko et al, 2010) (evidence level 2-) and one RCT (Verwaal et al, 2008; evidence level 1-) published between 2004 and 2010 met our inclusion criteria and were included in the meta-analysis. The included studies comprised a total of 342 patients with CPM, of whom 187 were treated with CRS + HIPEC and 155 received standard treatment with SC alone. Table 1 provides a summary of study design and treatment protocols for included studies. In three of the studies HIPEC was administered intraoperatively, commencing immediately after CRS (Verwaal et al, 2008; Elias et al, 2009; Franko et al, 2010) with duration of treatment ranging from 30 to $100 \mathrm{~min}$. In one study, intraperitoneal chemotherapy was administered from the first postoperative day onwards (early postoperative intraperitoneal chemotherapy, EPIC) for a variable duration (Mahteme et al, 2004). The intraperitoneal chemotherapeutic agent was mitomycin $\mathrm{C}$ (MMC) in two of the studies (Verwaal et al, 2008; Franko et al, 2010). Elias et al (2009) used a bidirectional protocol consisting of intraperitoneal Oxaliplatin and intravenous 5-fluorouracil (5-FU) and Leucovorin. Mahteme et al (2004) administered IV Leucovorin 60 min into the initiation of intraperitoneal chemotherapy with 5 -FU. In the study by Verwaal et al (2008) 105 patients with CPM were randomised to SC alone
(5-FU + Leucovorin; $n=51)$ or CRS + HIPEC (MMC; $n=54)$ treatment arms. Importantly, all patients in the CRS + HIPEC group received adjuvant chemotherapy (5-FU + Leucovorin). The study by Elias et al (2009) compared outcomes following CRS + HIPEC $(n=48)$ and SC alone for treatment of CPM. All patients in the CRS + HIPEC treatment arm received neoadjuvant (NA) chemotherapy, and only patients who demonstrated no evidence of disease progression after 3-4 months of NA therapy were included.

Patient selection. The primary indication for treatment was defined as the presence of peritoneal metastases of colorectal origin in all four of the studies included. Age as a means of patient selection was restricted to $<75$ years (Mahteme et al, 2004), $<71$ years (Verwaal et al, 2008), and $<66$ years (Elias et al, 2009) in different studies. Patients with 'extensive' and/or 'significantly symptomatic' CPM were deemed ineligible for study enrolment in two of the studies (Mahteme et al, 2004; Elias et al, 2009). More precise definitions were not provided with respect to assessment of resectability in these two studies. Patients with lung/liver metastases or other extra-abdominal disease were excluded in two studies (Mahteme et al, 2004; Verwaal et al, 2008), whereas two studies included patients with limited liver metastases (Elias et al, 2009; Franko et al, 2010). Three of the studies only included patients deemed to be of good general functional status (Mahteme et al, 2004; Verwaal et al, 2008; Elias et al, 2009). This classification was further defined in only two of the studies, with normal bone marrow indices and renal and liver function tests regarded as components of the eligibility criteria for one study, whereas an American Society of Anaesthesiology score of 1 or 2 was regarded as inclusion criteria for another of the studies included in this meta-analysis (Mahteme et al, 2004; Verwaal et al, 2008). Study recruitment was restricted to patients aged $<75$ years (Mahteme et al, 2004), <71 years (Verwaal et al, 2008), and $<66$ years (Elias et al, 2009) in different studies.

Survival. Survival outcome data are summarised in Table 2. Mahteme et al (2004) reported vastly superior 2- and 5-year survival following CRS + HIPEC compared with SC alone.

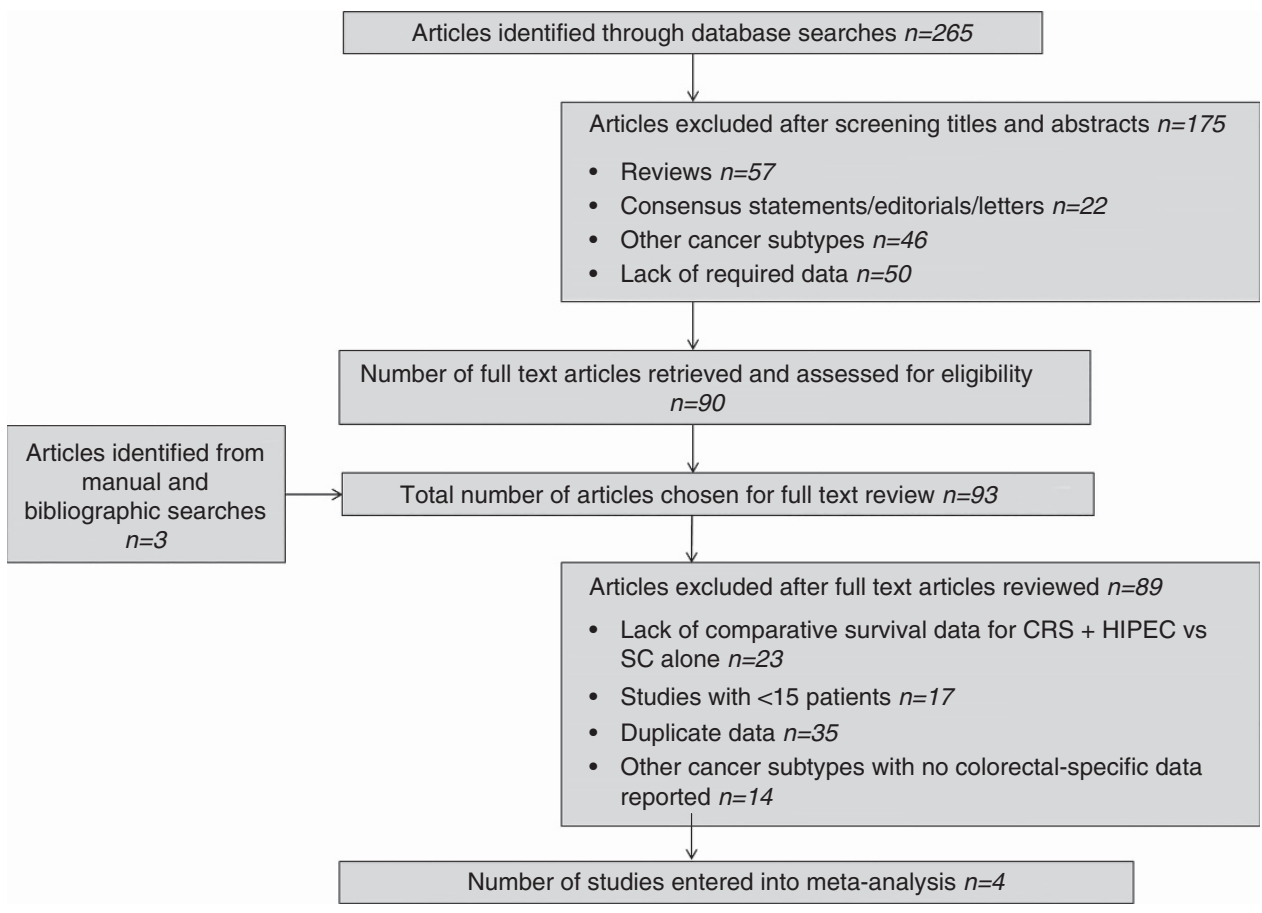

Figure 1. Modified PRISMA flow diagram summarising search strategy. 
Table 1. Study design and treatment protocols

\begin{tabular}{|c|c|c|c|c|c|c|c|c|}
\hline $\begin{array}{l}\text { Author, } \\
\text { year, } \\
\text { location }\end{array}$ & $\begin{array}{l}\text { Time } \\
\text { frame }\end{array}$ & $N$ & $\begin{array}{l}\text { Study design } \\
\text { (evidence } \\
\text { level) }\end{array}$ & Indication & Extent of CPM & $\begin{array}{l}\text { Treatment } \\
\text { summary }\end{array}$ & Technique & $\begin{array}{l}\text { Intraperitoneal } \\
\text { chemotherapeutic } \\
\text { regimen }\end{array}$ \\
\hline $\begin{array}{l}\text { Mahteme } \\
\text { et al, 2004, } \\
\text { Sweden }\end{array}$ & 1991-1999 & $\begin{array}{c}36 \\
\text { (18 vs 18) }\end{array}$ & Case-control (2-) & $\mathrm{CPM}^{\mathrm{a}}$ & - & $\begin{array}{l}\text { Treatment arm: } \\
\text { CRS + EPIC }(n=18) \\
\text { Control arm: } \\
\text { SC }(n=18)\end{array}$ & $\begin{array}{l}\text { Closed } \\
\text { abdomen } \\
\text { technique }\end{array}$ & $\begin{array}{l}\text { EPIC protocol: } \\
\text { 5-FU } 550 \mathrm{mg} \mathrm{m}^{-2} \text { in } 500 \mathrm{ml} \\
\text { normal saline administered } \\
\text { intraperitoneally from POD } 1 . \\
\text { IV infusion of leucovorin } \\
\left(60 \mathrm{mg} \mathrm{m}^{-2}\right) \text { commenced at } \\
60 \mathrm{~min} \text { after initiation of PIC. } \\
\text { Regimen offered } 1-8 \text { courses } \\
\text { as tolerated with } 4-6 \text { week } \\
\text { interval between cycles. } \\
\text { SC protocol: } \\
\text { chemotherapeutic regimen } \\
\text { not specified }\end{array}$ \\
\hline $\begin{array}{l}\text { Verwaal } \\
\text { et al, 2008, } \\
\text { Netherlands }\end{array}$ & 1998-2001 & $\begin{array}{c}105 \\
\text { (54 vs } 51)\end{array}$ & $\begin{array}{l}\text { Randomised trial } \\
\text { (1-) }\end{array}$ & $\mathrm{CPM}^{\mathrm{a}}$ & - & $\begin{array}{l}\text { Treatment arm: } \\
\text { CRS + HIPEC } \\
(n=54) \\
\text { Control arm: } \\
\text { systemic CT only } \\
(n=51)\end{array}$ & $\begin{array}{l}\text { Open } \\
\text { coliseum } \\
\text { technique }\end{array}$ & $\begin{array}{l}\text { HIPEC protocol: } \\
\text { MMC } 35 \mathrm{mg} \mathrm{m}^{-2} \text { at } 40^{\circ} \mathrm{C} \text { for } \\
90 \mathrm{~min} \\
\text { SC protocol: } \\
5 \text {-FU }\left(400 \mathrm{mg} \mathrm{m}^{-2}\right)+ \\
\text { leucovorin }\left(80 \mathrm{mg} \mathrm{m}^{-2}\right) \\
\text { weekly for } 26 \text { weeks }\end{array}$ \\
\hline $\begin{array}{l}\text { Elias et al, } \\
\text { 2009, } \\
\text { France }\end{array}$ & 1998-2003 & $\begin{array}{c}96 \\
(48 \text { vs } 48)\end{array}$ & Case-control (2-) & $\mathrm{CPM}^{\mathrm{b}}$ & $\begin{array}{l}\text { Treatment arm: } \\
\text { limited 27/48 } \\
\text { Extended } 21 / 48 \\
\text { Control arm: } \\
\text { Limited } 26 / 48 \\
\text { Extended 17/48 } \\
\text { Not recorded 5/48 }\end{array}$ & $\begin{array}{l}\text { Treatment arm: } \\
\text { CRS + HIPEC } \\
(n=48) \\
\text { Control arm: } \\
\text { SC }(n=48)\end{array}$ & - & $\begin{array}{l}\text { HIPEC protocol: } \\
\text { Oxaliplatin } 460 \mathrm{mg} \mathrm{m}^{-2} \text { in } \\
2 \mathrm{Im}^{-2} \text { at } 43^{\circ} \mathrm{C} \text { for } 30 \mathrm{~min} \text {. } \\
\text { Before HIPEC (during CRS) } \\
\text { patients received IV 5-FU } \\
400 \mathrm{mg} \mathrm{m}^{-2}+\text { leucovorin } \\
20 \mathrm{mg} \mathrm{m}^{-2} \text {. } \\
\mathrm{SC} \text { protocol: } \\
\text { Various regimens (5-FU- } \\
\text { based } 46 / 48 \text {; Capecitabine- } \\
\text { based } 1 / 48 \text {; Camptothecin } \\
1 / 48 \text { ) }\end{array}$ \\
\hline $\begin{array}{l}\text { Franko et al, } \\
\text { 2010, USA }\end{array}$ & $2001-2007$ & $\begin{array}{l}105(67 \\
\text { vs 38) }\end{array}$ & Case-control (2-) & $\mathrm{CPM}^{\mathrm{a}}$ & - & $\begin{array}{l}\text { Treatment arm: } \\
\text { CRS + HIPEC }(n=67) \\
\text { Control arm: } \\
\text { SC }(n=38)\end{array}$ & $\begin{array}{c}\text { Closed } \\
\text { abdomen } \\
\text { technique }\end{array}$ & $\begin{array}{l}\text { HIPEC protocol: } \\
\text { MMC } 40 \mathrm{mg} \text { for } 100 \mathrm{~min} \\
\text { SC protocol: } \\
\text { Chemotherapeutic regimen(s) } \\
\text { not clearly described }\end{array}$ \\
\hline
\end{tabular}

Subanalysis of survival in patients treated with CRS + HIPEC found 5-year survival of 37 and $14 \%$ in cases of macroscopically radical and incomplete resection, respectively. Similarly, Verwaal et al (2008) reported overall 2- and 5-year survival of 40 and 19\% in patients treated with CRS + HIPEC, compared with $22 \%$ and $10 \%$, respectively, for patients receiving SC alone. The authors found survival to correlate significantly with the completeness of cytoreduction, with 5 -year survival of $45 \%, 8 \%$, and $0 \%$ in patients undergoing R1 (complete macroscopic tumour clearance), R2a (residual tumour nodules $<2.5 \mathrm{~mm}$ in thickness), and $\mathrm{R} 2 \mathrm{~b}$ (residual tumour nodules $>2.5 \mathrm{~mm}$ in thickness) resection, respectively. Elias et al (2009) reported 2- and 5-year survival and median survival of $81 \%, 51 \%$, and 62.7 months, respectively, in 48 patients undergoing CRS + HIPEC compared with 48 matched patients receiving SC alone $(65 \%, 13 \%$ and 23.9 months, respectively). No data were available for survival according to extent of CPM or completeness of resection. Franko et al (2010) reported the median survival of 34.7 months in patients treated with CRS + HIPEC, compared with 16.8 months with SC alone $(P<0.001)$. Forest plots summarising pooled analysis of survival outcomes at 2 and 5 years with CRS + HIPEC vs SC alone are shown in Figures 2 and 3. Heterogeneity analysis revealed no significant between-study inconsistencies (2-year data: $Q$-value 3.14; df (Q) 3; P-value 0.377; $I^{2} 4.33$; 5 -year data: $Q$-value 2.66; $\mathrm{df}$ (Q); $3 ; P$-value $\left.0.488 ; I^{2} 0.00\right)$, and consequently estimates for OR and corresponding CI were derived using the FEM. Our metaanalysis demonstrated a significant improvement in 2-year survival with CRS + HIPEC compared with SC alone $(\mathrm{OR}=2.78$; 95\% CI $1.72-4.51 ; P=0.001$; funnel plot analysis shown in Figure 2). Similarly, meta-analysis of 5-year survival data from the four included studies revealed significantly enhanced survival at 5 years in patients treated with CRS + HIPEC compared with SC alone $(\mathrm{OR}=4.07 ; 95 \%$ CI 2.17-7.64; $P=0.001$; Figure 3$)$.

Morbidity, mortality, patient reported outcome measures, and health economics. Two of the four studies provided morbidity and mortality data (Mahteme et al, 2004; Verwaal et al, 2008). Mahteme et al (2004) reported overall treatment-associated morbidity and mortality of $72 \%$ and $0 \%$, respectively. Complications attributed to treatment with CRS + HIPEC in this study 
included severe postoperative pain $(4 / 18,22 \%)$, persistent nausea and vomiting $(2 / 18,11 \%)$, transient neutropenia $(1 / 18,5.5 \%)$, prolonged ileus $(1 / 18,5.5 \%)$, and postoperative bowel obstruction (5/18, 27.5\%). Verwaal et al (2008) reported a mortality rate of $7 \%$ $(4 / 54)$ in the CRS and HIPEC group in the only randomised study in this field. In all cases this was secondary to the development of postoperative complications that included abdominal sepsis in two cases. Complications in this study were reported according to the WHO criteria, with an overall complication rate of $7 \%$ in 54 patients undergoing CRS + HIPEC. Specifically, the most common grade 3 toxicities reported were leukopenia (15\%), heart failure (8\%), haemorrhage $(6 \%)$, and catheter-related infections $(6 \%)$. The most common grade 4 toxicities were intestinal fistulae (15\%), haemorrhage $(8 \%)$, and renal failure (6\%). Massive pulmonary embolus occurred in $4 \%$. The remaining two studies included in this metaanalysis did not provide morbidity or mortality outcome data (Elias et al, 2009; Franko et al, 2010). Neither of the studies evaluated provided any published QOL/patient-reported outcome measures or health economic data for evaluation. Data from the one RCT in this field, however, were available for economic evaluation and were provided by the authors. Cost effectiveness calculations were conducted based on both medical and non-medical impact of the treatments and revealed that in an intention to treat analysis, the average CRS and HIPEC treatment was $€ 17286.00$ ( $£ 14334.81$; $\$ 24,005.07)$ more expensive than SC treatment. The additional costs of treatment were found to be consequent to the complications in the experimental arm and the resulting prolonged hospital stay (Verwaal, 2003).

\begin{tabular}{|c|c|c|c|c|}
\hline & \multicolumn{4}{|c|}{ Survival (\%) } \\
\hline $\begin{array}{l}\text { Treatment } \\
\text { protocol }\end{array}$ & $\begin{array}{l}\text { Mahteme } \\
\text { et al, } 2004\end{array}$ & $\begin{array}{l}\text { Verwaal } \\
\text { et al, } 2008\end{array}$ & $\begin{array}{c}\text { Elias et al, } \\
2009\end{array}$ & $\begin{array}{l}\text { Franko } \\
\text { et al, } 2010\end{array}$ \\
\hline \multicolumn{5}{|l|}{2 Years } \\
\hline $\begin{array}{l}\text { SC } \\
\text { CRS }+ \text { HIPEC }\end{array}$ & $\begin{array}{l}10 \\
60\end{array}$ & $\begin{array}{l}22 \\
40\end{array}$ & $\begin{array}{l}65 \\
81\end{array}$ & $\begin{array}{l}41 \\
66\end{array}$ \\
\hline \multicolumn{5}{|l|}{5 Years } \\
\hline $\begin{array}{l}\mathrm{SC} \\
\mathrm{CRS}+\mathrm{HIPEC}\end{array}$ & $\begin{array}{r}5 \\
28\end{array}$ & $\begin{array}{l}10 \\
19\end{array}$ & $\begin{array}{l}13 \\
51\end{array}$ & $\begin{array}{r}5 \\
26\end{array}$ \\
\hline $\begin{array}{l}\text { Abbreviations: } \\
\text { motherapy; } \mathrm{SC}=\end{array}$ & $\begin{array}{l}=\text { cytoreductive } \\
\text { temic chemothe }\end{array}$ & $\begin{array}{l}\text { urgery; HIPEC }= \\
\text { py. }\end{array}$ & yperthermic intra & peritoneal che- \\
\hline
\end{tabular}

\section{DISCUSSION}

Peritoneal metastasis from CRC presents significant challenges. Without treatment, all patients with CPM can expect to have an exceptionally impaired quality of life (QOL) and abbreviated survival. Conventional surgical resection in the context of CPM has not shown effectiveness and is associated with a median survival limited to 6 months or less (Mohamed et al, 2011). Similarly, orthodox systemic chemotherapeutic (SC) strategies for CPM have demonstrated limited efficacy, at least in part owing to the plasmaperitoneal barrier that significantly restricts intraperitoneal drug localisation.

For these reasons, alternative strategies have been sought, and aggressive multimodality treatment with CRS combined with HIPEC is one tactic proposed as a logical treatment strategy to improve long-term survival. In the past, this approach has been rarely applied due to concerns regarding treatment-associated morbidity and mortality and health-care-related costs and logistics (Khatri, 2010; Sugarbaker and Ryan, 2012). In more recent times, however, advances in radiological staging, surgical and anaesthetic practice, improved experience in chemotherapeutic methods, better management of surgical complications and chemotherapyrelated toxicity, and an increasing centralisation of complex cancer services have helped expand the treatment options for patients with CPM, and improved the results of CRS and HIPEC in this setting.

Despite a recent consensus statement published on the role of CRS and HIPEC (Esquivel et al, 2007), there remains disagreement regarding the precise role of this multimodality approach in the treatment algorithm for CPM. In view of the ongoing debate, the aim of the present study was to perform meta-analytical assessment of medium- and long-term survival outcomes in patients with CPM treated with CRS and HIPEC compared with SC alone, which has hitherto represented the mainstay of treatment. Data from four studies, comprising three case-control studies and one RCT, with a cumulative total of 342 patients, were subjected to pooled analysis. We specifically excluded any data on patients with mucinous appendiceal peritoneal metastases receiving CRS and HIPEC because of the significant variation in the natural history and prognosis of this subgroup of patients (Sugarbaker and Jablonski, 1995).

Our pooled analysis demonstrates, for the first time, a significant improvement in survival at 2 and 5 years following CRS + HIPEC compared with standard treatment. This finding is likely explained by two fundamental points; first, the CRS component by definition leads to a reduction in tumour volume, which has long been recognised as an important determinant of tumour response to chemotherapy (Cotte et al, 2009). Second, the instillation of hyperthermic chemotherapeutic agents into the
Study name

$\begin{array}{lcccc} & \begin{array}{c}\text { Odds } \\ \text { ratio }\end{array} & \begin{array}{c}\text { Lower } \\ \text { limit }\end{array} & \begin{array}{c}\text { Upper } \\ \text { limit }\end{array} & P \text {-value } \\ \text { Mahteme et al } & 12.571 & 2.187 & 72.268 & 0.005 \\ \text { Verwaal et al } & 2.340 & 0.980 & 5.587 & 0.055 \\ \text { Elias et al } & 2.376 & 0.932 & 6.056 & 0.070 \\ \text { Franko et al } & 2.630 & 1.161 & 5.960 & 0.020 \\ \text { FEM } & 2.783 & 1.716 & 4.511 & 0.001\end{array}$

\section{Odds ratio and $95 \% \mathrm{Cl}$}

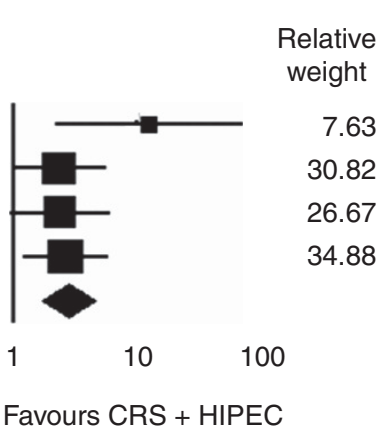

Figure 2. Summary of meta-analysis results for 2-year survival following CRS + HIPEC vs SC alone. The diamond represents the overall treatment effect, and squares are treatment effects for individual studies with $95 \% \mathrm{Cl}$ indicated by horizontal bars. 


\begin{tabular}{llrrrr} 
Study name & \multicolumn{5}{c}{ Statistics for each study } \\
& $\begin{array}{l}\text { Odds } \\
\text { ratio }\end{array}$ & $\begin{array}{c}\text { Lower } \\
\text { limit }\end{array}$ & $\begin{array}{c}\text { Upper } \\
\text { limit }\end{array}$ & $P$-value \\
Mahteme et al & 6.538 & 0.679 & 62.987 & 0.104 \\
Verwaal et al & 2.095 & 0.661 & 6.642 & 0.209 \\
Elias et al & 7.000 & 2.510 & 19.521 & 0.000 \\
Franko et al & 6.120 & 1.330 & 28.165 & 0.020 \\
FEM & 4.599 & 2.387 & 8.860 & 0.001
\end{tabular}

\section{Odds ratio and $95 \% \mathrm{Cl}$}

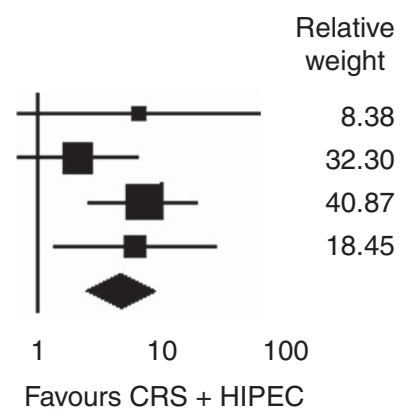

Figure 3. Summary of meta-analysis results for 5 -year survival following CRS + HIPEC vs SC alone. The diamond represents the overall treatment effect, and squares are treatment effects for individual studies with $95 \% \mathrm{Cl}$ indicated by horizontal bars.

peritoneal cavity after CRS aims to destroy any remaining tumour cells and mitigates problems associated with poor peritoneal penetration achieved by conventional chemotherapy. Thus, these strategies in combination represent a highly logical and synergistic approach for the management of CPM.

The incremental contributions of either CRS or HIPEC to improved survival independently within this multimodality approach remain unclear from the currently available literature. A recent study by Huang et al (2013) compared outcomes in 29 patients undergoing CRS alone, with 33 patients treated with CRS and HIPEC in combination. All patients received adjuvant SC with FOLFOX or FOLFIRI regimens. The authors found significantly improved 1-, 2-, and 3-year survival in patients treated with CRS + HIPEC compared with CRS alone. A multicentre French randomised trial (PRODIGE 7) comparing CRS and HIPEC against CRS only for CPM with a PCI stage of less than 24 has recently completed accrual, and preliminary results are awaited. To date, no trial has evaluated outcomes with HIPEC in isolation vs CRS + HIPEC or SC only; however, such a study may not be forthcoming, given what is currently known regarding the association between tumour bulk reduction and chemotherapeutic effectiveness. With regards to SC alone for treatment of CPM, an unavoidable problem, even with newer chemotherapeutic agents and targeted therapies, lies in the fact that patients with peritoneal malignancy frequently develop bowel obstruction, which will, in many cases, prohibit completion of therapy. It is unclear from the data evaluated in the present study what proportion of patients receiving SC in isolation had their treatment courses truncated because of such complications.

Several misapprehensions must be set aside in order for CRS + HIPEC to be accepted as 'gold standard' therapy for selected patients with CPM. First, it has been suggested that the evidence base to support the role of CRS + HIPEC is limited. However, we would contend that unlike the management of hepatic and pulmonary metastases from CRC, which have never been subjected to randomised evaluation and currently represent the standard of care, there are level 1 data available showing the advantages conferred by CRS and HIPEC compared with SC alone. Moreover, this finding is further endorsed by all the case-control studies evaluated in the present meta-analysis.

Second, it has been suggested that the morbidity and mortality associated with CRS + HIPEC is unacceptably high. However, without this aggressive approach, the median survival from CPM seldom exceeds 6 months, and this abbreviated period is frequently beset by symptoms of severe abdominal pain and bowel obstruction, as well as systemic toxic consequences associated with SC. Unquestionably, the combination of extensive multivisceral resection, prolonged operation time, and intraperitoneal chemotherapy will confer a considerable potential for surgical complications, toxicity, and impairment of QOL. The most feared treatment-associated complications identified include fistula formation, anastomotic dehiscence, postoperative bleeding, nephrotoxicity, and haematological complications. However, improvements in anaesthesia, operative technique, critical care, and diagnostic and interventional radiology are facilitating better results through early recognition and active treatment of complications, with several recent large-scale studies now reporting acceptable morbidity and mortality following CRS + HIPEC (Canda et al, 2013; Bakrin et al, 2013). In addition, more effective means of predicting likely treatment-associated morbidity and mortality are emerging, which will further improve patient selection (Ihemelandu et al, 2013). For example, a recent study by Ihemelandu et al (2013) found that preoperative use of the Functional Assessment of Cancer Therapy questionnaire combined with Eastern Cooperative Oncology Group performance allowed enhanced prediction of treatment-associated morbidity and mortality. Furthermore, a recent study by Passot et al (2013). evaluated QOL following CRS + HIPEC for peritoneal carcinomatosis and found, as expected, a reduction in QOL in the first 6 months after aggressive multimodality therapy. However, the authors also noted that QOL returned to baseline at 12 months post CRS + HIPEC, by which time few, if any, patients not receiving radical treatment would be expected to have survived.

With respect to health-care costs associated with CRS + HIPEC, only one study included in this meta-analysis provided expenserelated data (Verwaal, 2003). Results of this intention to treat analysis showed that CRS and HIPEC treatment was $€ 17286.00$ more costly than SC, with the additional expenses principally because of development of complications necessitating prolonged hospital stay. A limited number of other studies have also performed cost-effectiveness analysis, but in a non-comparative setting. For example, Chua et al (2010) performed cost-effectiveness analysis on 136 consecutive patients who underwent a total of 159 CRS + HIPEC procedures over a 6-year period at a single tertiary referral centre. They reported average costs per patient and per life year of AUD \$66 148 and AUD \$29757, respectively, for patients treated with CRS + HIPEC for CPM. The authors concluded that this treatment approach is associated with increased medical care costs, but that these costs are offset by the treatment-associated gains in observed life years. In the medium term, the additional costs associated with CRS and HIPEC will likely further diminish, because of improved patient selection for radical treatment, and with increasingly better management of treatment-related complications, in line with most complex surgical interventions.

There are a number of both limitations and strengths to the present analysis. All but one of the studies evaluated in this metaanalysis were non-randomised comparative studies with small to modest sample sizes, and not the highest quality evidence. Nevertheless, it remains unclear whether meta-analyses of non- 
randomised studies systematically overestimate effect sizes compared with meta-analyses of randomised trials (MacLehose et al, 2000 ), and in light of the scarcity of high-quality evidence in this field, data from the meta-analysis of non-randomised studies can be informative. A further criticism is that the studies examined showed significant variability with respect to the extent of peritoneal disease in affected patients, its manner of assessment, treatment protocols, and the type of chemotherapy applied. Clearly therefore our findings must be interpreted with a degree of caution, nevertheless through combining data, the effect of bias within individual studies may also be mitigated partly. Importantly, our findings do not advocate resection of all cases of CPM but highlight the importance of selection criteria used and the advantages of judicious patient assessment. Better methods of patient selection are clearly necessary, however, and the role of physiological testing preoperatively may well merit further study to more effectively gauge functional capacity and risk of adverse events. In addition, several studies have shown a clear association between extent of disease and oncological outcome (Verwaal et al, 2004), highlighting the urgent need for more precise radiological methods for preoperative assessment of disease location and burden. Current CT- or FDG-PET-based methods of cancer evaluation are dependent on the amount of tumour per square centimetre and are thought to generally underestimate the extent of peritoneal surface malignancy, which will often not fulfill the RESIST criteria of $1 \mathrm{~cm}$ in diameter for measurable disease (Verwaal et al, 2008). In addition, an important challenge on the horizon will be to identify methods to avoid over-treatment in patients with chemotherapy-insensitive tumours, and to limit side effects in those with chemosensitive disease. The exact type of chemotherapy and its method of administration also remain unclear at the present time, as is the precise contribution of CRS or HIPEC to the favourable outcomes observed. A further key question will be whether different/more radical/dose-escalated HIPEC/intraperitoneal chemotherapy regimens can counter unfavourable peritoneal disease extent scores. Robust molecular biomarkers of oncological outcome and disease response are clearly required and are presently lacking. Exciting developments in the molecular sciences and the multi-platform high-throughput methods increasingly applied to diverse tumour types are slowly revolutionising established treatment approaches, and raise hopes of a more personalised strategy in the future treatment of CPM. The currently active molecularly stratified COMBATAC multicentre trial in CPM may help further advance this field and address some of the questions in the near future (Glockzin et al, 2013).

In summary, the present meta-analysis indicates that, although the evidence base for adoption of CRS and HIPEC is generally composed of low evidence level studies from uncontrolled retrospective series, there are comparative and prospective studies available, and arguably a greater body of data exists for this treatment option than has been available to support the use of metastatectomy for liver and lung metastases of CRC origin. Moreover, the available studies consistently demonstrate survival and symptom control rates far greater than any available alternative, justifying an aggressive multimodality approach. Consequently, analogous to the acceptance of surgery for liver and lung metastatic CRC, surgery for CPM should have an established place in selected patients and offers the only realistic chance of long-term survival. Indeed, a case could be made that the biological arguments for treatment of peritoneal only metastases are more persuasive than those for surgery of CRC that has metastasised to distant organs. Metastasis to distant organs is a consequence of a complicated multistep process, wherein cells acquire the ability to invade beyond normal cellular boundaries, intravasate into blood and lymphatics, journey to distant organs, extravasate and proliferate in a different microenvironment, concomitantly eluding antitumour host immunity. By contrast,
CPM arising from the shedding and exfoliation of CRC cells able to survive and grow on the peritoneal surface, but which lack the capacity to disseminate, is more likely to represent a better prognostic tumour type, by lacking the molecular capacity to spread to distant organs. Greater recognition of the concept of curative CPM should ultimately lead to earlier referral to specialist units, resulting in improved completeness of resection and better survival outcomes.

\section{CONCLUSIONS}

The present meta-analysis demonstrates a clear and significant improvement in survival at 2 and 5 years following CRS + HIPEC compared with SC alone. The studies included are small in number and of variable methodological quality, with only one RCT. Nevertheless, our findings support a growing body of data that suggests that CRS + HIPEC can result in survival rates greater than any alternative. Management decisions for CPM are complex, and treatment requires multidisciplinary, multimodality approaches. In view of these complexities, optimal assessment and management is best undertaken by specialist units able to provide the breadth of expertise and options required. Importantly, the present study has also identified a number of unanswered questions to inform the design of future studies. To address these, high-number, multiinstitutional studies with limited heterogeneity in assessment and treatment protocols will better enable clarification of some of the remaining controversies in the treatment of CPM, and serve as a platform for incremental advances towards the optimal treatment of metastatic CRC.

\section{ACKNOWLEDGEMENTS}

AHM is supported by grant funding from Cancer Research UK (C28503/A10013). This study was funded by the Cancer Research UK and Royal College of Surgeons of England.

\section{CONFLICT OF INTEREST}

The authors declare no conflict of interest.

DISCLAIMER

The funding sources had no role in the collection, analyses, interpretation of data, writing of the report, or decision to publish.

\section{REFERENCES}

Bakrin N, Bereder JM, Decullier E, Classe JM, Msika S, Lorimier G, Abboud K, Meeus P, Ferron G, Quenet F, Marchal F, Gouy S, Morice P, Pomel C, Pocard M, Guyon F, Porcheron J, Glehen O (2013) Peritoneal carcinomatosis treated with cytoreductive surgery and Hyperthermic Intraperitoneal Chemotherapy (HIPEC) for advanced ovarian carcinoma: a French multicentre retrospective cohort study of 566 patients. Eur J Surg Oncol 39: 1435-1443.

Brucher BL, Piso P, Verwaal V, Esquivel J, Derraco M, Yonemura Y, Gonzalez-Moreno S, Pelz J, Konigsrainer A, Strohlein M, Levine EA, Morris D, Bartlett D, Glehen O, Garofalo A, Nissan A (2012) Peritoneal carcinomatosis: cytoreductive surgery and HIPEC-overview and basics. Cancer Invest 30: 209-224.

Canda AE, Sokmen S, Terzi C, Arslan C, Oztop I, Karabulut B, Ozzeybek D, Sarioglu S, Fuzun M (2013) Complications and toxicities after cytoreductive surgery and hyperthermic intraperitoneal chemotherapy. Ann Surg Oncol 20: 1082-1087. 
Chu DZ, Lang NP, Thompson C, Osteen PK, Westbrook KC (1989) Peritoneal carcinomatosis in nongynecologic malignancy. A prospective study of prognostic factors. Cancer 63: 364-367.

Chua TC, Martin S, Saxena A, Liauw W, Yan TD, Zhao J, Lok I, Morris DL (2010) Evaluation of the cost-effectiveness of cytoreductive surgery and hyperthermic intraperitoneal chemotherapy (peritonectomy) at the St George Hospital peritoneal surface malignancy program. Ann Surg 251: 323-329.

Cotte E, Passot G, Mohamed F, Vaudoyer D, Gilly FN, Glehen O (2009) Management of peritoneal carcinomatosis from colorectal cancer: current state of practice. Cancer J 15: 243-248.

Cunningham D, Atkin W, Lenz HJ, Lynch HT, Minsky B, Nordlinger B, Starling N (2010) Colorectal cancer. Lancet 375: 1030-1047.

Cunningham D, Humblet Y, Siena S, Khayat D, Bleiberg H, Santoro A, Bets D, Mueser M, Harstrick A, Verslype C, Chau I, Van Cutsem E (2004) Cetuximab monotherapy and cetuximab plus irinotecan in irinotecanrefractory metastatic colorectal cancer. $N$ Engl J Med 351: 337-345.

Egger M, Davey Smith G, Schneider M, Minder C (1997) Bias in meta-analysis detected by a simple, graphical test. BMJ 315: 629-634.

Elias D, Lefevre JH, Chevalier J, Brouquet A, Marchal F, Classe JM, Ferron G, Guilloit JM, Meeus P, Goere D, Bonastre J (2009) Complete cytoreductive surgery plus intraperitoneal chemohyperthermia with oxaliplatin for peritoneal carcinomatosis of colorectal origin. J Clin Oncol 27: 681-685.

Esquivel J, Sticca R, Sugarbaker P, Levine E, Yan TD, Alexander R, Baratti D, Bartlett D, Barone R, BARRIOS P, Bieligk S, Bretcha-Boix P, Chang CK, Chu F, Chu Q, Daniel SDE, Bree E, Deraco M, Dominguez-Parra L, Elias D, Flynn R, Foster J, Garofalo A, Gilly FN, Glehen O, Gomez-Portilla A, Gonzalez-Bayon L, Gonzalez-Moreno S, Goodman M, Gushchin V, Hanna N, Hartmann J, Harrison L, Hoefer R, Kane J, Kecmanovic D, Kelley S, Kuhn J, Lamont J, Lange J, Li B, Loggie B, Mahteme H, Mann G, Martin R, Misih RA, Moran B, Morris D, Onate-Ocana L, Petrelli N, Philippe G, Pingpank J, Pitroff A, Piso P, Quinones M, Riley L, Rutstein L, Saha S, Alrawi S, Sardi A, Schneebaum S, Shen P, Shibata D, Spellman J, Stojadinovic A, Stewart J, Torres-Melero J, Tuttle T, Verwaal V, Villar J, Wilkinson N, Younan R, Zeh H, Zoetmulder F, Sebbag G (2007) Cytoreductive surgery and hyperthermic intraperitoneal chemotherapy in the management of peritoneal surface malignancies of colonic origin: a consensus statement. Society of Surgical Oncology. Ann Surg Oncol 14: $128-133$.

Ferlay J, Steliarova-Foucher E, Lortet-Tieulent J, Rosso S, Coebergh JW, Comber H, Forman D, Bray F (2013) Cancer incidence and mortality patterns in Europe: estimates for 40 countries in 2012. Eur J Cancer 49 : 1374-1403.

Franko J, Ibrahim Z, Gusani NJ, Holtzman MP, Bartlett DL, Zeh 3rd HJ (2010) Cytoreductive surgery and hyperthermic intraperitoneal chemoperfusion versus systemic chemotherapy alone for colorectal peritoneal carcinomatosis. Cancer 116: 3756-3762.

Glehen O, Gilly FN, Boutitie F, Bereder JM, Quenet F, Sideris L, Mansvelt B, Lorimier G, Msika S, Elias D (2010) Toward curative treatment of peritoneal carcinomatosis from nonovarian origin by cytoreductive surgery combined with perioperative intraperitoneal chemotherapy: a multi-institutional study of 1,290 patients. Cancer 116: 5608-5618.

Glockzin G, Rochon J, Arnold D, Lang SA, Klebl F, Zeman F, Koller M, Schlitt HJ, Piso P (2013) A prospective multicenter phase II study evaluating multimodality treatment of patients with peritoneal carcinomatosis arising from appendiceal and colorectal cancer: the COMBATAC trial. BMC Cancer 13: 67.

Guyot P, Ades AE, Ouwens MJ, Welton NJ (2012) Enhanced secondary analysis of survival data: reconstructing the data from published KaplanMeier survival curves. BMC Med Res Methodol 12: 9.

Harbour R, Miller J (2001) A new system for grading recommendations in evidence based guidelines. BMJ 323: 334-336.

Higgins JP, Thompson SG (2002) Quantifying heterogeneity in a meta-analysis. Stat Med 21: 1539-1558.

Higgins JP, Thompson SG, Deeks JJ, Altman DG (2003) Measuring inconsistency in meta-analyses. BMJ 327: 557-560.

Huang CQ, Feng JP, Yang XJ, Li Y (2013) Cytoreductive surgery plus hyperthermic intraperitoneal chemotherapy improves survival of patients with peritoneal carcinomatosis from colorectal cancer: A case-control study from a Chinese center. J Surg Oncol 109(7): 730-739.

Ihemelandu CU, Mcquellon R, Shen P, Stewart JH, Votanopoulos K, Levine EA (2013) Predicting postoperative morbidity following cytoreductive surgery with hyperthermic intraperitoneal chemotherapy (CS + HIPEC) with preoperative FACT-C (Functional Assessment of Cancer Therapy) and patient-rated performance status. Ann Surg Oncol 20: 3519-3526.

Jacquet P, Sugarbaker PH (1996) Clinical research methodologies in diagnosis and staging of patients with peritoneal carcinomatosis. Cancer Treat Res 82: $359-374$.

Jayne DG, Fook S, Loi C, Seow-Choen F (2002) Peritoneal carcinomatosis from colorectal cancer. Br J Surg 89: 1545-1550.

Khatri VP (2010) Cytoreductive surgery and hyperthermic intraperitoneal chemotherapy for colorectal cancer: a panacea or just an obstacle course for the patient? J Clin Oncol 28: 5-7.

Kuijpers AM, Mirck B, Aalbers AG, Nienhuijs SW, de Hingh IH, Wiezer MJ, Van Ramshorst B, Van Ginkel RJ, Havenga K, Bremers AJ, De Wilt JH, Te Velde EA, Verwaal VJ (2013) Cytoreduction and HIPEC in the Netherlands: nationwide long-term outcome following the Dutch protocol. Ann Surg Oncol 20: 4224-4230.

Lee S, Kim DY, Kim SY, Koom WS, Lee SY, Kang JK, Kim MS (2013) Curative radiotherapy using different radiation techniques for isolated lung metastasis from colorectal cancer. Tumori 99: 68-75.

MacLehose RR, Reeves BC, Harvey IM, Sheldon TA, Russell IT, Black AM (2000) A systematic review of comparisons of effect sizes derived from randomised and non-randomised studies. Health Technol Assess 4: $1-154$.

Mahteme H, Hansson J, Berglund A, Pahlman L, Glimelius B, Nygren P, Graf W (2004) Improved survival in patients with peritoneal metastases from colorectal cancer: a preliminary study. $\mathrm{Br} J$ Cancer 90: 403-407.

Mohamed F, Cecil T, Moran B, Sugarbaker P (2011) A new standard of care for the management of peritoneal surface malignancy. Curr Oncol 18: e84-e96.

Moher D, Liberati A, Tetzlaff J, Altman DG (2009) Preferred reporting items for systematic reviews and meta-analyses: the PRISMA statement. BMJ 339: b2535.

Nordlinger B, Sorbye H, Glimelius B, Poston GJ, Schlag PM, Rougier P, Bechstein WO, Primrose JN, Walpole ET, Finch-Jones M, Jaeck D, Mirza D, Parks RW, Mauer M, Tanis E, Van Cutsem E, Scheithauer W, Gruenberger T (2013) Perioperative FOLFOX4 chemotherapy and surgery versus surgery alone for resectable liver metastases from colorectal cancer (EORTC 40983): long-term results of a randomised, controlled, phase 3 trial. Lancet Oncol 14: 1208-1215.

Passot G, Bakrin N, Roux AS, Vaudoyer D, Gilly FN, Glehen O, Cotte E (2013) Quality of life after cytoreductive surgery plus hyperthermic intraperitoneal chemotherapy: A prospective study of 216 patients. Eur J Surg Oncol 40(5): 529-535.

Riss S, Mohamed F, Dayal S, Cecil T, Stift A, Bachleitner-Hofmann T, Moran B (2013) Peritoneal metastases from colorectal cancer: patient selection for cytoreductive surgery and hyperthermic intraperitoneal chemotherapy. Eur J Surg Oncol 39: 931-937.

Sadeghi B, Arvieux C, Glehen O, Beaujard AC, Rivoire M, Baulieux J, Fontaumard E, Brachet A, Caillot JL, Faure JL, Porcheron J, Peix JL, Francois Y, Vignal J, Gilly FN (2000) Peritoneal carcinomatosis from non-gynecologic malignancies: results of the EVOCAPE 1 multicentric prospective study. Cancer 88: 358-363.

Song F, Sheldon TA, Sutton AJ, Abrams KR, Jones DR (2001) Methods for exploring heterogeneity in meta-analysis. Eval Health Prof 24: 126-151.

Sugarbaker PH (1999) Successful management of microscopic residual disease in large bowel cancer. Cancer Chemother Pharmacol 43(Suppl): S15-S25.

Sugarbaker PH, Jablonski KA (1995) Prognostic features of 51 colorectal and 130 appendiceal cancer patients with peritoneal carcinomatosis treated by cytoreductive surgery and intraperitoneal chemotherapy. Ann Surg 221: 124-132.

Sugarbaker PH, Ryan DP (2012) Cytoreductive surgery plus hyperthermic perioperative chemotherapy to treat peritoneal metastases from colorectal cancer: standard of care or an experimental approach? Lancet Oncol 13: e362-e369.

Sutton AJ, Duval SJ, Tweedie RL, Abrams KR, Jones DR (2000) Empirical assessment of effect of publication bias on meta-analyses. BMJ 320: 1574-1577.

Tampellini M, Ottone A, Bellini E, Alabiso I, Baratelli C, Bitossi R, Brizzi MP, Ferrero A, Sperti E, Leone F, Miraglia S, Forti L, Bertona E, Ardissone F, Berruti A, Alabiso O, Aglietta M, Scagliotti GV (2012) The role of lung metastasis resection in improving outcome of colorectal cancer patients: results from a large retrospective study. Oncologist 17: 1430-1438.

van Dijk TH, Tamas K, Beukema JC, Beets GL, Gelderblom AJ, De Jong KP, Nagtegaal ID, Rutten HJ, Van De Velde CJ, Wiggers T, Hospers GA, 
Havenga K (2013) Evaluation of short-course radiotherapy followed by neoadjuvant bevacizumab, capecitabine, and oxaliplatin and subsequent radical surgical treatment in primary stage IV rectal cancer. Ann Oncol 24: $1762-1769$.

Verwaal V (2003) Cytoreduction and hyperthermic intraperitoneal chemotherapy in peritoneal carcinomatosis of colorectal origin. Ph.D. Thesis. University of Amsterdam: The Netherlands, ISBN 90-6464-580-9.

Verwaal VJ, Bruin S, Boot H, Van Slooten G, Van Tinteren H (2008) 8-year follow-up of randomized trial: cytoreduction and hyperthermic intraperitoneal chemotherapy versus systemic chemotherapy in patients with peritoneal carcinomatosis of colorectal cancer. Ann Surg Oncol 15: 2426-2432.

Verwaal VJ, Van Tinteren H, Van Ruth S, Zoetmulder FA (2004) Predicting the survival of patients with peritoneal carcinomatosis of colorectal origin treated by aggressive cytoreduction and hyperthermic intraperitoneal chemotherapy. Br J Surg 91: 739-746.

Yi JH, Kim H, Jung M, Shin SJ, Choi JS, Choi GH, Baik SH, Min BS, Kim NK, Ahn JB (2013) Prognostic factors for disease-free survival after preoperative chemotherapy followed by curative resection in patients with colorectal cancer harboring hepatic metastasis: a single-institute, retrospective analysis in Asia. Oncology 85: 283-289.

This work is published under the standard license to publish agreement. After 12 months the work will become freely available and the license terms will switch to a Creative Commons AttributionNonCommercial-Share Alike 3.0 Unported License. 